\title{
Article \\ Structural Evolution of Nanophase Separated Block Copolymer Patterns in Supercritical $\mathrm{CO}_{2}$
}

\author{
Tandra Ghoshal ${ }^{1, *}$, Timothy W. Collins ${ }^{2,3,4}$, Subhajit Biswas ${ }^{2,3,4}$, Michael A. Morris ${ }^{1}$ and Justin D. Holmes ${ }^{2,3,4}$ \\ 1 School of Chemistry, AMBER and CRANN, Trinity College Dublin, D02 AK60 Dublin, Ireland; \\ MORRISM2@tcd.ie \\ 2 School of Chemistry, University College Cork, T12 YN60 Cork, Ireland; \\ collins.incorporated@gmail.com (T.W.C.); s.biswas@ucc.ie (S.B.); j.holmes@ucc.ie (J.D.H.) \\ 3 Tyndall National Institute, University College Cork, T12 YN60 Cork, Ireland \\ 4 AMBER Centre, Environmental Research Institute, University College Cork, T23 XE10 Cork, Ireland \\ * Correspondence: g_tandra@yahoo.co.in or ghoshalt@tcd.ie
}

Citation: Ghoshal, T.; Collins, T.W.; Biswas, S.; A. Morris, M.; Holmes, J.D. Structural Evolution of Nanophase Separated Block Copolymer Patterns in Supercritical $\mathrm{CO}_{2}$. Nanomaterials 2021, 11, 669. https://doi.org/ 10.3390/nano11030669

Academic Editor: Arthur P. Baddorf

Received: 5 February 2021

Accepted: 4 March 2021

Published: 8 March 2021

Publisher's Note: MDPI stays neutral with regard to jurisdictional claims in published maps and institutional affiliations.

\begin{abstract}
Nanopatterns can readily be formed by annealing block copolymers (BCPs) in organic solvents at moderate or high temperatures. However, this approach can be challenging from an environmental and industrial point of view. Herein, we describe a simple and environmentally friendly alternative to achieve periodically ordered nanoscale phase separated BCP structures. Asymmetric polystyrene- $b$-poly(ethylene oxide) (PS- $b$-PEO) thin film patterns of different molecular weight were achieved by annealing in supercritical carbon dioxide $\left(\mathrm{sc}-\mathrm{CO}_{2}\right)$. Microphase separation of PS- $b$-PEO $(16,000-5000)$ film patterns were achieved by annealing in $\mathrm{scCO}_{2}$ at a relatively low temperature was previously reported by our group. The effects of annealing temperature, time and depressurisation rates for the polymer system were also discussed. In this article, we have expanded this study to create new knowledge on the structural and dimensional evolution of nanohole and line/space surface periodicity of four other different molecular weights PS- $b$-PEO systems. Periodic, well defined, hexagonally ordered films of line and hole patterns were obtained at low $\mathrm{CO}_{2}$ temperatures $\left(35-40{ }^{\circ} \mathrm{C}\right)$ and pressures (1200-1300 psi). Further, the changes in morphology, ordering and feature sizes for a new PS- $b$-PEO system $(42,000-11,500)$ are discussed in detail upon changing the $\mathrm{scCO}_{2}$ annealing parameters (temperature, film thickness, depressurization rates, etc.). In relation to our previous reports, the broad annealing temperature and depressurisation rate were explored together for different film thicknesses. In addition, the effects of SCF annealing for three other BCP systems (PEO- $b$-PS, PS- $b$-PDMS, PS- $b$-PLA) is also investigated with similar processing conditions. The patterns were also generated on a graphoepitaxial substrate for device application.
\end{abstract}

Keywords: block copolymer; $\mathrm{scCO}_{2}$ annealing; microphase separation; structural evolution; feature size variation

\section{Introduction}

Block copolymers (BCPs) are quintessential nanostructure forming materials due to their self-organizing capabilities [1]. This provides a large variety of potential technological applications such as nanolithography and "bottom up" microelectronic device fabrication depending on their different ordered morphologies produced after microphase separation $[2,3]$. Composition (block ratio, molecular weight, interaction parameters) and temperature are the controlling factors which determine the different morphologies of BCPs [1] In thin film form, typically obtained by spin-casting or dip-coating procedures, interfacial energies between air and a solid substrate as well as the film thickness relative to the bulk periodicity are additional factors which also determine the morphology of a BCP [3-6]. Generally, Solvent annealing is utilised to obtain ordered phase-separated, nanostructured thin films at low temperatures and in relatively short time periods through swelling the polymer blocks by a solvent, providing the necessary chain mobility and free volume to the 
blocks for microphase separation [7,8]. Organic and halogenated solvents are commonly used to swell one or more blocks within a polymer film even though they are toxic and have a negative environmental impact [9]. Removal of excess solvent is also necessary for many technological and biological applications concerning sensitivity [10-13]. In addition, achieving a stable ordered structure with a controlled orientation throughout a very large area of a substrate is challenging. In contrary, supercritical carbon dioxide $\left(\mathrm{scCO}_{2}\right)$ is an attractive solvent (or diluent) for the phase separation of $\mathrm{BCPs}$ as the fluid increases the free volume and chain mobility of dense polymers, thereby reducing the melt viscosity $\left(T_{\mathrm{g}}\right)$ and melting point $\left(T_{\mathrm{m}}\right)$ and facilitating the formation of self-assembled nanostructures [14-16]. Furthermore, the solvation and transport properties of $\mathrm{scCO}_{2}$ can be finely adjusted via modest changes in pressure or temperature [17-19]. The desirable qualities of $\mathrm{CO}_{2}$ include low cost, wide availability, moderate critical conditions (critical temperature $(T \mathrm{c})=31^{\circ} \mathrm{C}$, critical pressure $(P \mathrm{c})=73.8 \mathrm{bar}$ and critical density $\left.(\rho \mathrm{c})=0.468 \mathrm{~g} . \mathrm{cm}^{-3}\right)$, environmentally and chemically (volatile, inert, non-flammable) benign nature, low interfacial tension and complete elimination of the gas after process termination [20-22].

However, phase ordering and kinetics of $\mathrm{BCP}$ films by $\mathrm{scCO}_{2}$ have been examined from both a theoretical and an experimental perspective, but no clear evidence to support the formation of nanostructured surface periodic arrangements in BCPs annealed at low temperatures in $\mathrm{scCO}_{2}$ has been realised [23-25]. A few reports on $\mathrm{BCP}$ surface structure formation in $\mathrm{scCO}_{2}$ have been reported, but this was largely achieved by annealing polymers above their melting points $[15,25,26]$.

Microphase separation of polystyrene-b-polyethylene oxide (PS- $b$-PEO) BCP films into nanostructured arrangement by annealing in $\mathrm{scCO}_{2}$ at a relatively low temperature was achieved by our group [27]. The effects of annealing temperature and depressurisation rates for one of the BCP systems were discussed previously. Herein, the structural and dimensional evolution of nanohole and line/space surface periodicity for four different molecular weights PS- $b$-PEO systems, upon changing the $\mathrm{scCO}_{2}$ annealing parameters (temperature, pressure, time, film thickness, etc.) is highlighted. Compared to our previous reports, a broad annealing temperature and depressurisation rate ranges were explored to achieve structural evolution along with for different film thicknesses. The effects of $\mathrm{BCP}$ nanopatterns for three other BCP systems was also investigated with similar processing conditions. We also discuss the differentiation in the interaction parameters of $\mathrm{scCO}_{2}$ with the polymers and thereby the changes in the glass transition temperatures of the $\mathrm{BCP}$ films causing microphase separation. The patterns were also generated on a graphoepitaxial substrate for device application.

\section{Materials and Methods}

Polystyrene- $b$-poly(ethylene oxide) (PS- $b$-PEO) diblock copolymers were purchased from Polymer Source Inc., Dorval, QC, Canada and used without further purification. Toluene and acetone were purchased from Sigma-Aldrich, Wicklow, Ireland. Four different molecular weight $\mathrm{BCPs}$ were explored with number-average molecular weights of (i) $M_{\mathrm{n}}, \mathrm{PS}=9.5 \mathrm{~kg} \mathrm{~mol}^{-1}, \mathrm{PEO}=5 \mathrm{~kg} \mathrm{~mol}^{-1}, M_{\mathrm{w}} / M_{\mathrm{n}}=1.08$; (ii) $M_{\mathrm{n}}, \mathrm{PS}=20 \mathrm{~kg} \mathrm{~mol}^{-1}$, $\mathrm{PEO}=6.5 \mathrm{~kg} \mathrm{~mol}^{-1}, M_{\mathrm{w}} / M_{\mathrm{n}}=1.05$; (iii) $M_{\mathrm{n}}, \mathrm{PS}=42 \mathrm{~kg} \mathrm{~mol}^{-1}, \mathrm{PEO}=11.5 \mathrm{~kg} \mathrm{~mol}^{-1}$, $M_{\mathrm{w}} / M_{\mathrm{n}}=1.07$ and (iv) $M_{\mathrm{n}}, \mathrm{PS}=102 \mathrm{~kg} \mathrm{~mol}^{-1}, \mathrm{PEO}=34 \mathrm{~kg} \mathrm{~mol}^{-1}, M_{\mathrm{w}} / M_{\mathrm{n}}=1.09$, where $M_{\mathrm{W}}$ is the weight-average molecular weight. Single crystal B doped silicon (100) wafers with a native oxide layer were used as substrates. These wafers were cleaned by ultrasonication in acetone and toluene (Sigma-Aldrich, Wicklow, Ireland) for $30 \mathrm{~min}$ in each solvent and dried under a nitrogen stream. PS- $b$-PEO was dissolved in toluene to yield a $0.8 \mathrm{wt} \%$ polymer solution which was aged for $12 \mathrm{~h}$ at room temperature. PS- $b$ PEO thin films were formed by spin coating the polymer solution at different spin speed for $30 \mathrm{~s}$ onto a Si wafer. Spin coating speeds were varied to accomplish different film thicknesses. Polymer coated wafer were subsequently loaded into a stainless-steel highpressure vessel ( $5 \mathrm{~mL}$, High pressure equipment, PA, USA), which was sealed and placed into a preheated oven (purchased from Thermo Fisher Scientific, UK) at temperatures 
ranging between 35 and $60{ }^{\circ} \mathrm{C}$ and pressurised with $\mathrm{CO}_{2}$ at a rate $0.5 \mathrm{~mL} \mathrm{~min}{ }^{-1}$, using a manual pressure generator (ISCO HPLC pump, Teledyne, Lincon, USA). Annealing of the polymer thin films was carried out in $\mathrm{scCO}_{2}$ at a constant temperature (oven temperature) and pressure (1000-1400 psi). After the desired time, the annealing chamber was removed and cooled naturally before the $\mathrm{CO}_{2}$ pressure was released at a typical depressurisation rate of $40 \mathrm{psi} \mathrm{min}^{-1}$ with a pressure controller. Depressurisation was also undertaken at rates of 20,30,60 and $120 \mathrm{psi} / \mathrm{min}$ to understand its effects on BCP morphologies and the microphase separation process. The microphase separated structures were produced on graphoepitaxial substrate.

Surface morphologies of BCP thin films were imaged by scanning probe microscopy (SPM, Park systems, XE-100, Japan) in tapping mode. The film thicknesses were measured by optical ellipsometry (Woolam M2000, Lincoln, USA) at a fixed angle of $70^{\circ}$ for a minimum of five different locations on the sample. Average values were reportesd as the measured thickness value. A two-layer model $\left(\mathrm{SiO}_{2}+\mathrm{BCP}\right)$ was used to simulate experimental data. Samples were prepared for TEM cross sectional imaging with an FEI Helios Nanolab 600i system containing a high resolution Elstar ${ }^{\mathrm{TM}}$ Schottky field-emission SEM and a Sidewinder FIB column (purchased from Oregon, USA). A gold protective layer was deposited on top of the film surface before FIB processing. Further platinum e-beam and ion beam was deposited during FIB cross-section. The sectioned Si substrate was transferred to a TEM grid and imaged by transmission electron microscopy (TEM, JEOL 2100, Netherlands).

\section{Results and Discussion}

\subsection{Dimensional and Structural Control of Block Copolymer Nanopatterns}

Dimensional and structural control over the self-assembled block copolymer nanopatterns was achieved using different molecular weight PS- $b$-PEO systems; the compositions of the constituent blocks are represented as S1 (9500-5000), S2 (20,000-6500), S3 (42,000$11,500)$ and S4 $(102,000-34,000)$. Polymeric solutions were spin coated onto substrates at a spin speed of $3000 \mathrm{rpm}$ for $30 \mathrm{~s}$. The as-coated BCP films formed poorly ordered micelles for S1, S2 compositions whereas S3 exhibited little indication of periodic ordering at room temperature. Poorly ordered microphase separation without any controlled orientation was observed for S4 films. To achieve microphase separation, annealing of the polymer thin films was carried out in $\mathrm{scCO}_{2}$ at different temperatures, pressures, holding times and depressurisation rates. Figure 1 shows topographic AFM images of the PS- $b$-PEO systems after annealing in $\mathrm{scCO}_{2}$ for $30 \mathrm{~min}$ at a temperature of $40{ }^{\circ} \mathrm{C}$. The images show ordered arrangements over large areas for all polymer compositions with no indication of de-wetting. In the AFM images, the PEO cylinders are darker in colour due to its much lower glass transition temperature $\left(T_{\mathrm{g}}\right)\left(-60^{\circ} \mathrm{C}\right)$ compared to $105^{\circ} \mathrm{C}$ for PS [28,29]. It is believed that the $\mathrm{PEO}$ becomes crystallized just after the spin-coating from toluene solution. Additionally, AFM measurements is carried out at room temperature and PEO domains is thought to be softer (semi molten state) than PS regime as reported values of Young's moduli of PS and PEO were 5.2 and $0.2 \mathrm{GPa}$, respectively [30]. Therefore, the darker regions must represent the PEO cylinders as the depression of the domains are higher compared to PS during AFM measurement. BCP films with compositions of S1 and S2 were depressurised at a rate of $40 \mathrm{psi} \mathrm{min}^{-1}$ to achieve microphase separation and to control the orientation of the cylindrical domains generated. Figure 1a shows a microphase separated arrangement of hexagonal ordered PEO cylinders parallel to the substrate surface for an S1 polymer composition, whereas hexagonally ordered PEO cylinders with a perpendicular orientation were obtained for polymer films with an $\mathrm{S} 2$ composition under similar experimental conditions (Figure 1b). The average centre to centre spacings and PEO cylinder diameter were found to be $17 \mathrm{~nm}$ and $7 \mathrm{~nm}$, respectively for $\mathrm{S} 1$ polymer compositions and $37 \mathrm{~nm}$ and $22 \mathrm{~nm}$, respectively for S2 films. For the higher molecular weight polymer systems, i.e., S3 and S4, perpendicular cylinders of PEO cylinders were realised at a $\mathrm{ScCO}_{2}$ pressure of $1200 \mathrm{psi}$ and a depressurisation rate of $40 \mathrm{psi} \mathrm{min}^{-1}$ (Figure 1c,d, respectively). The mean 
centre to centre spacings were found to be $52 \mathrm{~nm}$ and $74 \mathrm{~nm}$ for S3 and S4 polymer systems, respectively. The mean PEO cylinder diameter was observed to be 28 and $38 \mathrm{~nm}$ for the S3 and S4 films, respectively. At a scCO $\mathrm{CO}_{2}$ pressure of $1400 \mathrm{psi}$, enhanced surface roughness, thickness variations and pattern degradation (pattern missing) were observed for all of the PS- $b$-PEO systems. The thickness of the films before and after annealing, as determined by optical ellipsometry, remained constant at 19,36, 52 and $72 \mathrm{~nm}$ for S1 to S4 compositions, respectively. Table 1 summarises the SCF annealing conditions, film thicknesses, measured pitch size and PEO cylinder diameters for different PS- $b$-PEO systems. No large scale surface roughness or thickness undulation across the surfaces of the films was noticed and the thickness of the films produced close emulated their domain spacing value. The morphology and interfaces of S3 polymer films was further analysed by cross sectional TEM. A plasma dry etching process was applied to partially remove the PEO domains to increase contrast between the ordered nanofeatures for cross-sectional TEM analysis. The insert of Figure 1c shows the wavy nature of the surface of a film due to partial etching of the PEO domains with a film thickness around $48 \mathrm{~nm}$. The non-selective etching treatment between PS and PEO reduced the film thickness. The arrangement of the PEO domain in the films continues to a definite depth within the film. The mean spacing of features was consistent with a domain spacing of $52 \mathrm{~nm}$ as previously measured by AFM. The wave structure was not perfectly periodic due to either/or both the non-selective nature of the etching and/or a non-perfect image projection (since the film may not have been cut exactly orthogonal to the holes). The mean diameter of the PEO domain was observed to be $30 \mathrm{~nm}$, due to broadening during the etching step. The film was strongly adhered to the substrate surface with no indication of deformation or delamination.

Table 1. Dimensional and structural control of block copolymer nanopatterns for different PS- $b$-PEO thin films systems under SCF annealing at $40{ }^{\circ} \mathrm{C}$ for $30 \mathrm{~min}$.

\begin{tabular}{ccccccc}
\hline $\begin{array}{c}\text { PS-b-PEO } \\
\text { (Molecular } \\
\text { Weight) }\end{array}$ & $\chi N$ & $\mathbf{f}_{\text {PEO }}$ & $\begin{array}{c}\text { SCF } \\
\text { Annealing } \\
\text { Pressure } \\
\text { (psi) }\end{array}$ & $\begin{array}{c}\text { Film } \\
\text { Thickness } \\
\text { (nm) }\end{array}$ & $\begin{array}{c}\text { Pitch Size } \\
\text { (nm) }\end{array}$ & $\begin{array}{c}\text { PEO } \\
\text { Cylinder } \\
\text { Diameter } \\
\text { (nm) }\end{array}$ \\
\hline $\begin{array}{c}9500-5000 \\
20,000-6500\end{array}$ & 11.21 & 0.341 & 1300 & 19 & 17 & 7 \\
$42,000-$ & 20.54 & 0.242 & 1300 & 36 & 37 & 22 \\
11,500 & 41.49 & 0.212 & 1200 & 52 & 52 & 28 \\
$102,000-$ & 105.42 & 0.247 & 1200 & 72 & 74 & 38 \\
34,000 & & & & & & \\
\hline
\end{tabular}

Figure 1e shows the variation of pitch size with the total molecular weight and PEO molecular weight for all of the PS- $b$-PEO systems studied. Both of the curves show an increment in pitch size with total and PEO molecular weight as expected.]. An exponential curve fitting for both the curves shows the relationship of pitch size for the BCP.

The variation of pitch size with the total molecular weight can be expressed as

$$
y=3.75123+4.56393 \mathrm{e}^{0.04551 x}
$$

The variation of pitch size with the PEO molecular weight can be expressed as

$$
y=4.05001+0.25786 \mathrm{e}^{0.06426 x}
$$




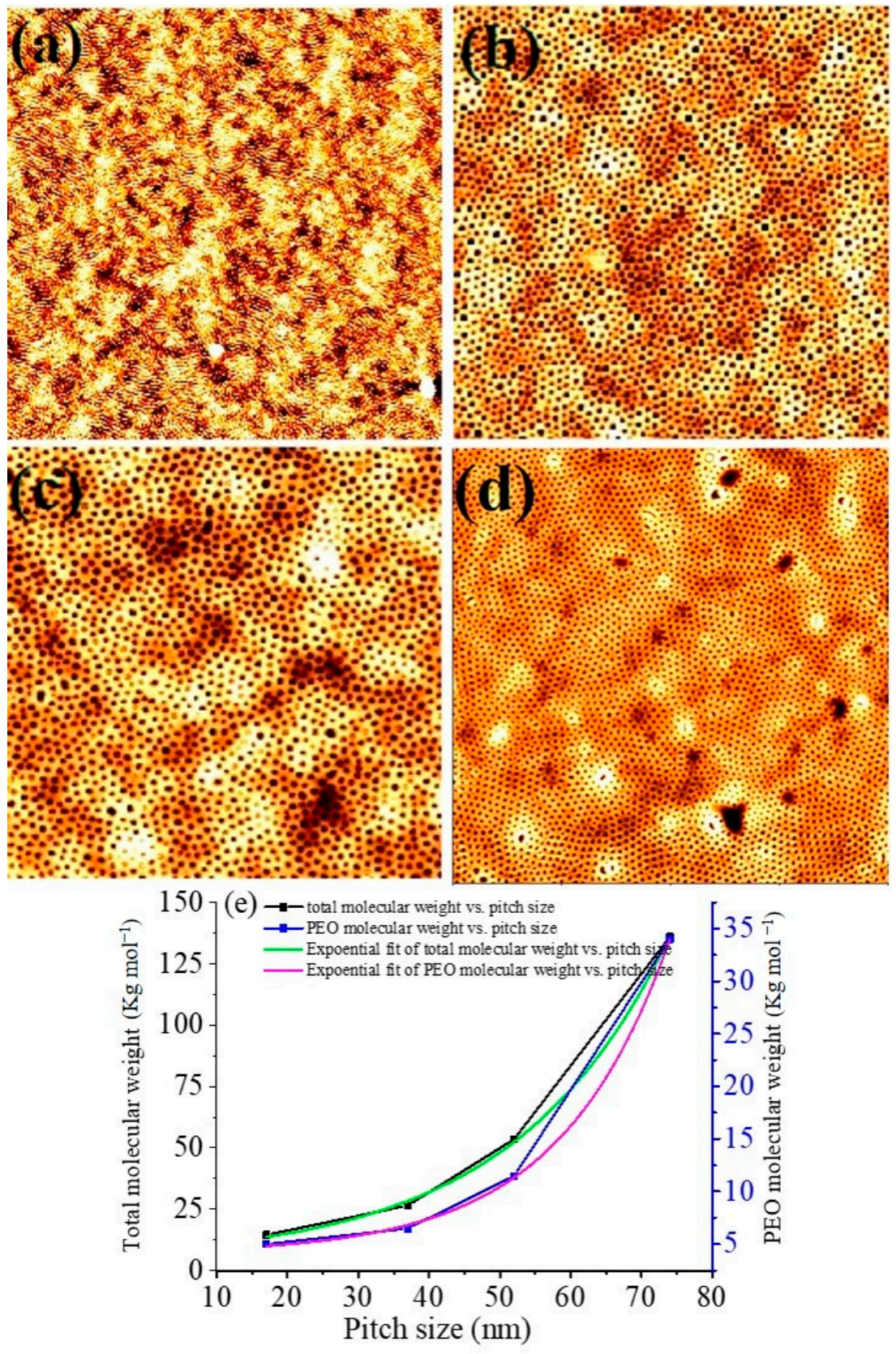

Figure 1. AFM topographic images of microphase separated PS- $b$-PEO thin films patterns under SCF annealing at $40^{\circ} \mathrm{C}$ for $30 \mathrm{~min}$ of different molecular weights of (a) 9500-5000, (b) 20,000-6500, (c) 42,000-11,500 and (d) 102,000-34,000. Scale bar: (a-c) $2 \mu \mathrm{m}^{2}$ and (d) $4 \mu \mathrm{m}^{2}$. Inset of (c) shows corresponding FIB thinned TEM image. (e) pitch size dependence with the total and PEO molecular weights for PS-PEO.

\subsection{Mechanism of Microphase Separation for Different BCP Systems}

Although both the PS and PEO blocks swell in $\mathrm{CO}_{2}$, the BCP films returns to their original thickness after complete removal of $\mathrm{CO}_{2}$. Microphase separated structures is achieved at relatively lower $\mathrm{CO}_{2}$ pressures for all of the molecular weight $\mathrm{BCPs}$, is due to the higher values of $\chi N(>10)$ ( $\chi$ is the Flory-Huggins interaction parameter and $N$ is the degree of polymerisation).

The $\chi$ parameter can be calculated as

$$
\chi=\frac{V_{p}\left(\delta_{1}-\delta_{2}\right)^{2}}{R T}
$$


where $V_{p}$ is the volume of one mole of polymer segments and $\delta$ is the solubility parameter. The calculated value of $\chi$ used in this study for the PS- $b$-PEO system is 0.081 . The measured $\chi N$ values were $11.21,20.54,41.49,105.42$ for S1, S2, S3 and S4, respectively. The higher molecular weight $\mathrm{BCP}$ systems requires lower external mediating or a thermodynamic driving force to achieve phase separation compared to lower molecular weight BCPs. This means comparatively lower free energy is required at higher $\chi N$ values to rearrange the polymer chains for achieving self-assembly. The parallel and perpendicular cylinder orientation is dictated by different volume fraction of the constituent blocks. For $\mathrm{S} 1$, the volume fraction of PS, $\mathrm{f}_{\mathrm{PS}}$ is 0.659 and the volume fraction of $\mathrm{PEO}, \mathrm{f}_{\mathrm{PEO}}$ is 0.341 . The $\mathrm{f}_{\mathrm{PS}}$ and $\mathrm{f}_{\mathrm{PEO}}$ values for $\mathrm{S} 2$, S3 and S4 are $0.758,0.242 ; 0.788,0.212$; and $0.753,0.247$, respectively. The agreement between volume fraction of minor component PEO over PS and the ratio of the areas of the cylinders and the matrix (from the AFM images) over flat surface, suggest that the ordered cylinders are most likely the PEO domains perpendicular to the surface while the matrix is of PS blocks. Figure 2 shows the calculated phase diagram ( $\chi N$ vs. $\mathrm{f}_{\mathrm{PEO}}$ ) of the $\mathrm{BCP}$ systems belongs to hexagonal cylindrical phase regime (superimposed on the original BCP phase diagram). Table 1 summarises the $\chi N$ values and the volume fractions of the PEO blocks ( $f_{\text {PEO }}$ ) for different PS- $b$-PEO systems. The equilibrium stability for vertical orientation is achieved by $\mathrm{scCO}_{2}$ annealing for the $\mathrm{f}_{\mathrm{PEO}}$ values equal to or less than 0.25 for S2, S3 and S4. Vertical orientation represents least entropically hindered route for microphase separation, since the PEO cylinder length is limited to the thickness of the films. Previous studies have shown that the swelling of $\mathrm{PEO}$ in $\mathrm{scCO}_{2}$ is between $20-25 \mathrm{wt} \%$, larger than that of PS (5-6 wt $\%$ ) at similar pressure of $1400 \mathrm{psi}[27,31-33]$. Thus, the swelling of the entire film is dominated by the swelling of the PEO microdomains compared to the PS block. The higher volume fraction of the PEO blocks for BCP with an S1 compositions imparts higher mobility to the PEO chains leading to an increment of Gibbs energy within the film due to an increase of the configurational freedom of the PEO chains. This increment in energy within the system easily orientates the cylinders parallel to the substrate which although entropically less favoured. Thus, the PS blocks serves as a majority surface block forming matrix through minimizing the free energy of the system maintaining the equilibrium stability. The exact thickness (relative to cylinder repeat distance) of the monolayer film is also preferred the parallel orientation. However, the selective enhancement of $\mathrm{CO}_{2}$ sorption within the PEO blocks compared to the substratepolymer and polymer-air interfaces overcomes film dewetting. Both the PS and PEO blocks were present at the polymer-air interface after $\mathrm{scCO}_{2}$ annealing due to reduced surface tension caused by higher solvent concentration inside the film.

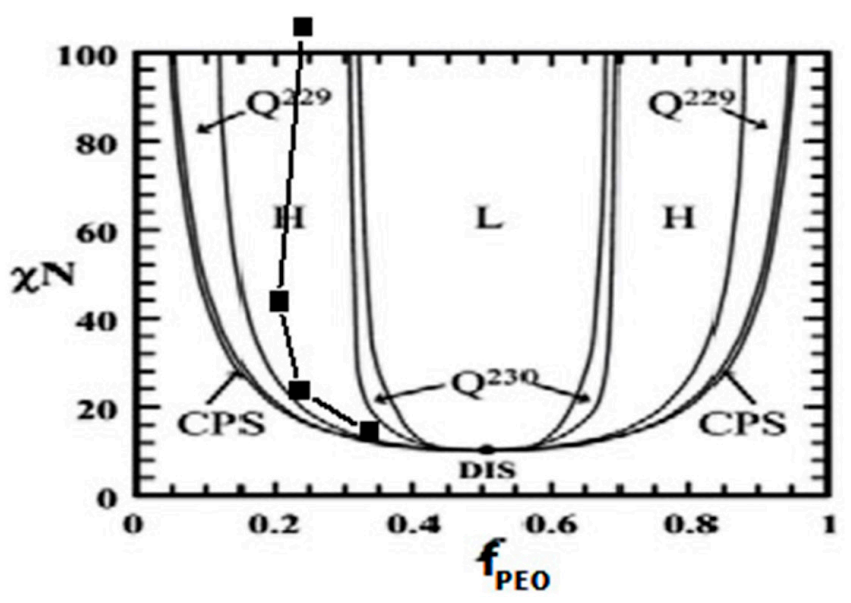

Figure 2. The calculated phase diagram $\left(\chi N\right.$ vs. $\left.\mathrm{f}_{\mathrm{PEO}}\right)$ of different PS- $b$-PEO BCP systems (superimposed on the original BCP phase diagram). 


\subsection{Formation of BCP Nanopatterns at Different SCF Annealing Temperatures}

The effects of annealing temperature on the microphase separation and ordered arrangement of the $\mathrm{S} 3 \mathrm{BCP}$ films was investigated as small change in the annealing temperature was found to alter the kinetics (solvation of $\mathrm{CO}_{2}$ into the polymer) of the polymer-fluid mixture under the same pressure [34]. Figure 3 shows the topographic AFM images of microphase separated surface structures of $\mathrm{S} 3$ polymer compositions annealed between temperatures of $35-60{ }^{\circ} \mathrm{C}$ for $30 \mathrm{~min}$ at a $\mathrm{scCO}_{2}$ pressure of $1200 \mathrm{psi}$. At a temperature of $35^{\circ} \mathrm{C}$, microphase separated structures with perpendicularly oriented PEO cylinders were formed in most locations on the films (see Figure 3a), but missing patterns (black spots) were also evident. The thickness of the film shown in Figure 3a is slightly higher which was around $55 \mathrm{~nm}$ compared to films prepared at $40^{\circ} \mathrm{C}$. At a temperature of $45^{\circ} \mathrm{C}$, phase separated well ordered BCP film with two different thicknesses of around $52 \mathrm{~nm}$ and $55 \mathrm{~nm}$ were formed (Figure 3b). Thicker fragments had larger cylinder diameters than thinner regions. Increasing the temperature to 50 and $60^{\circ} \mathrm{C}$, resulted in the formation of short parallel oriented PEO cylinders as well as perpendicularly orientated regions. Moreover, the PEO cylinders are with larger diameter at $50{ }^{\circ} \mathrm{C}$ (compared to lower temperature) whereas few of them flipped their orientation to parallel to the substrate (Figure 3c). More flipping tendency (to parallel) is noticed at the highest temperature of $60^{\circ} \mathrm{C}$ (Figure 3d). The increased disparity between the $\mathrm{CO}_{2}-\mathrm{PS}$ and $\mathrm{CO}_{2}-\mathrm{PEO}$ solubility and interfacial energies at high temperatures creates larger effective interaction parameter $\left(\chi_{\text {eff }}\right)$ irrespective of the film thickness, eases the process of phase separation. Previous reports suggests that the temperatures below $50{ }^{\circ} \mathrm{C}$ are more suitable to achieve phase separation under constant $\mathrm{CO}_{2}$ pressure conditions, consistent with our finding [27,32]. At a temperature of $60^{\circ} \mathrm{C}$, which is just above the melting temperature of the PEO block $\left(55^{\circ} \mathrm{C}\right)$ for the $\mathrm{S} 3$ molecular weight system, PEO is in a semi-molten state which facilitates the reorientation of the PEO cylinders and the morphological change [35]. Of note, the larger free energy at higher temperature can cause frequent structural transition in order to release the extra tension. The process of the forming nanopatterns by $\mathrm{scCO}_{2}$ annealing is relatively faster than that was reported for solvent (organic) annealing $[29,36]$. This is due to the influential reduction in the viscosity of $\mathrm{PEO}$ chains by $\mathrm{scCO}_{2}$ diffusion into the block which reaches to a critical value, thus permitting the polymer chains easily extend and/or relax to achieve phase separation. At high temperatures, the PEO chains extends and swell more compared as that of lower temperatures, further rapid removal of $\mathrm{scCO}_{2}$ during depressurisation shrinks back the film quickly leads to island formation of different thicknesses.

\subsection{Effects of Film Thicknesses by Varying Spin Coating Speed}

As discussed previously the change in film thickness during the self-assembly process significantly influences the final morphology, size and ordering of the $\mathrm{BCP}$ films. Figure 4 shows AFM images of BCP films with an $\mathrm{S} 3$ composition with varying spin coating speed after microphase separation, achieved by annealing in $\mathrm{scCO}_{2}$ at a temperature of $40{ }^{\circ} \mathrm{C}$ and a pressure of $1200 \mathrm{psi}$ for $30 \mathrm{~min}$. At all spin speeds between 1000-4000 rpm, microphase separated perpendicularly oriented PEO cylinders were formed inside the PS matrix. Variations in the thickness of the films, in the form of island was evident, throughout the films at all spin speeds investigated. The islands (black contrast) are thinner than the regular film (white) regions. Moreover, the frequency and size of the islands increased with increasing spin speed. At a low spin speed of $1000 \mathrm{rpm}$, the PEO cylinder diameters were $\sim 25 \mathrm{~nm}$ in most of the film areas, whereas the black contrast islands had larger diameters around $27 \mathrm{~nm}$ (Figure 4a). Increasing the spin speed to $2000 \mathrm{rpm}$, resulted in the formation of PEO cylinders in white film regions with a mean diameter of $27 \mathrm{~nm}$ compared to those in the black regions where the mean diameter was $29 \mathrm{~nm}$ (Figure $4 \mathrm{~b}$ ). At spin speeds of $3000 \mathrm{rpm}$, the mean diameters of the PEO cylinders in the white and dark regions were both found to be $28 \mathrm{~nm}$. Further increasing the spin speed to $4000 \mathrm{rpm}$ alters the mean cylinder diameter to 30 and $26 \mathrm{~nm}$ in the black and white film regions, respectively. (Figure 4c). The measured thickness of the films before and after phase separation were 
$59 \mathrm{~nm}, 55 \mathrm{~nm}$ and $50 \mathrm{~nm}$, for spin speeds of 1000, 2000 and $4000 \mathrm{rpm}$, respectively. The results are summarised in Table 2 . The differences in film thicknesses and uniformity in PEO cylinder diameter after microphase separation with the varying spin speed can be explained based on the trapped $\mathrm{scCO}_{2}$ during annealing. For different thickness of the films, the kinetics are different due to the vitrification of the film that alters the swelling behaviour of the blocks. The trapped solvent results in defects in the surface morphology by modification in the polymer-substrate, polymer-air and polymer-polymer interactions. The increased ordering and the uniformity of patterns for the thinnest films could be due to significantly less residual solvent and lack of a well-defined solvent front. For thicker films, longer time is required to evaporate the solvent due to combined effects of sufficiently large film thickness and attractive interaction of the solvent with the substrate [37]. The presence of significant amount of trapped solvent in thicker films may help to form the bigger island type structure due to two-dimensional Ostwald ripening type mechanisms [28]. The PEO cylinders swells and shrinks back faster through the release of trapped solvent for the islands with black contrast (thinner regions) than the thicker islands. Thus, thinner islands are with less cylinder diameter than white regions (more trapped solvents for thicker part) due to higher amount of PEO block swelling.

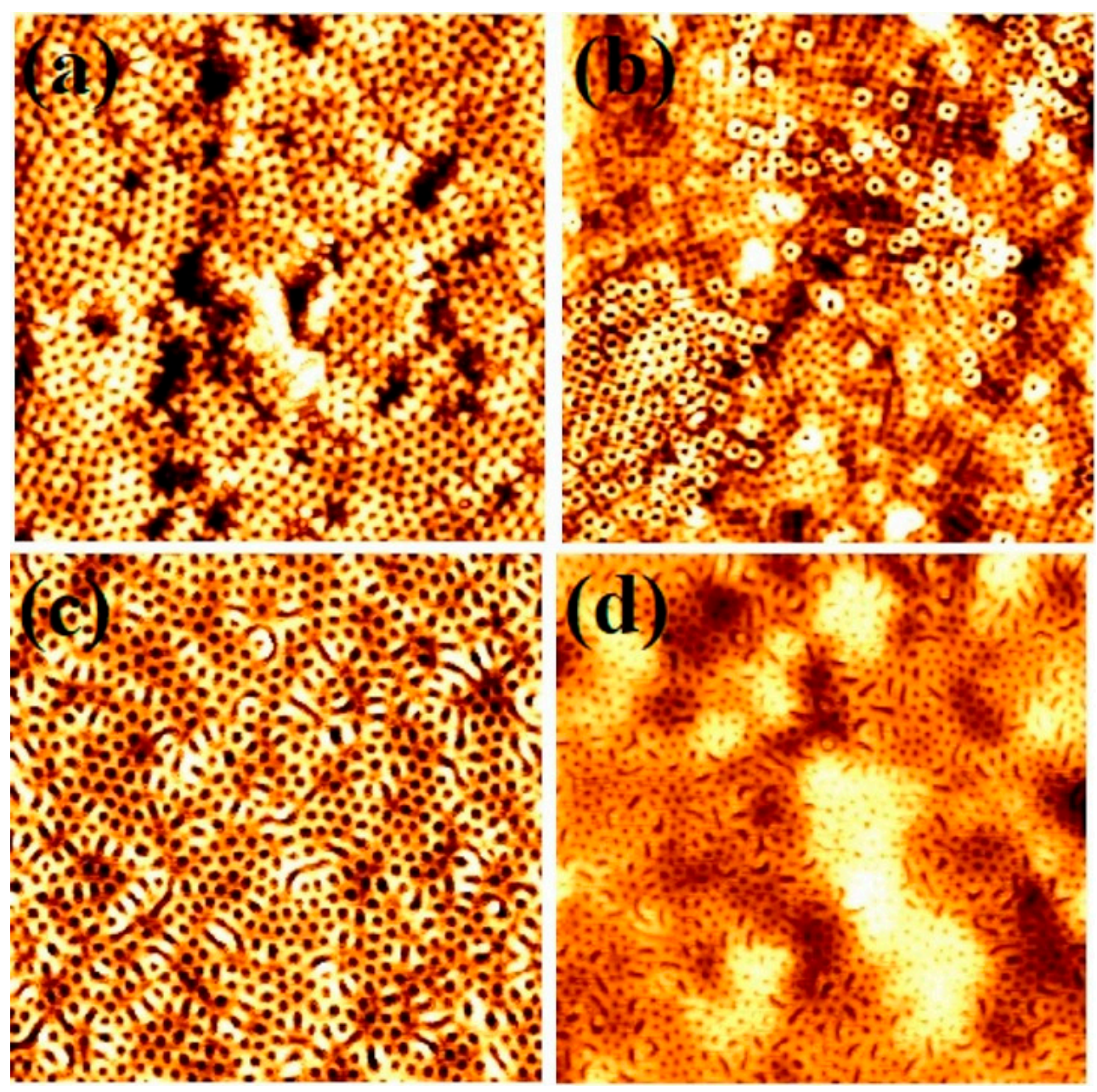

Figure 3. AFM topographic images of microphase separated 42,000-11,500 PS- $b$-PEO thin films patterns under SCF annealing for $30 \mathrm{~min}$ formed at different temperature of (a) $35^{\circ} \mathrm{C},(\mathbf{b}) 45^{\circ} \mathrm{C}$, (c) $50{ }^{\circ} \mathrm{C}$ and (d) $60^{\circ} \mathrm{C}$. Scale bar: $2 \mu \mathrm{m}^{2}$. 


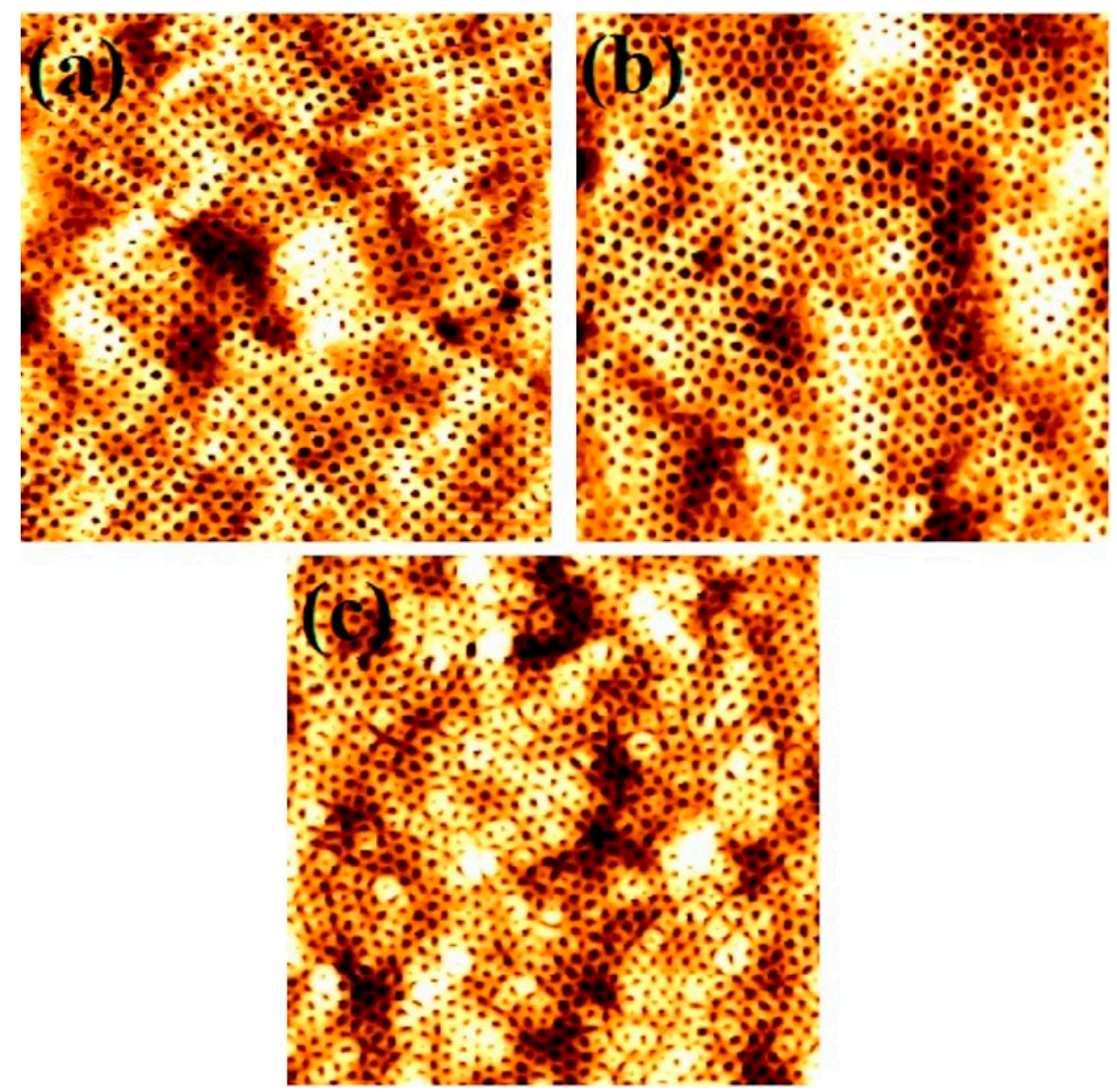

Figure 4. AFM topographic images of microphase separated 42,000-11,500 PS-b-PEO thin films patterns under SCF annealing at $40{ }^{\circ} \mathrm{C}$ for $30 \mathrm{~min}$ formed by spin coating with different spin speed of (a) $1000 \mathrm{rpm}$, (b) $2000 \mathrm{rpm}$ and (c) $4000 \mathrm{rpm}$. Scale bar: $2 \mu \mathrm{m}^{2}$.

Table 2. Effects of spin casting speed for S3 BCP system.

\begin{tabular}{cccc}
\hline $\begin{array}{c}\text { Spin Coating Speed } \\
(\mathbf{r p m})\end{array}$ & Film Thickness (nm) & $\begin{array}{c}\text { PEO Cylinder } \\
\text { Diameter (nm) in Black } \\
\text { Region }\end{array}$ & $\begin{array}{c}\text { PEO Cylinder } \\
\text { Diameter (nm) in } \\
\text { White Region }\end{array}$ \\
\hline 1000 & 59 & 27 & 25 \\
2000 & 55 & 29 & 27 \\
3000 & 52 & 28 & 28 \\
4000 & 50 & 30 & 26 \\
\hline
\end{tabular}

\subsection{Effects of Depressurisation Rate on the Self Assembly}

As previously reported, annealing $\mathrm{BCPs}$ in $\mathrm{scCO}_{2}$ effectively decreases their glass transition temperature $\left(T_{\mathrm{g}}\right)$, which plays an important role in their microphase separation and the creation of ordered patterns [17]. $T_{\mathrm{g}}$ of PEO is always below room temperature and $T_{\mathrm{g}}$ of $\mathrm{PS}$ is reported to be around $30^{\circ} \mathrm{C}_{\text {in }} \mathrm{scCO}_{2}$ [38]. At high depressurization rate, such as $120 \mathrm{psi} / \mathrm{min}$, depressions or holes on the surface of a films are readily formed [15]. Thus, it is convincing to study the effects of depressurisation rates on the internal structural transition as well as surface morphology of the BCP films. Figure 5 shows the surface and internal morphologies BCP films with an S3 composition after annealing in $\mathrm{CO}_{2}$ at a $\mathrm{CO}_{2}$ pressure of 1200 psi and a temperature of $40^{\circ} \mathrm{C}$ for $30 \mathrm{~min}$, with depressurization rates of $120,60,30$ and $20 \mathrm{psi} / \mathrm{min}$. At depressurisation rates of 120 and $60 \mathrm{psi} / \mathrm{min}$, wafer scale BCP films with hexagonally ordered PEO cylinders containing holes (dark spots in 
the AFM image) throughout their surface were observed. In addition, the non-uniform diameter of the PEO cylinders formed and thickness variation in the films were also noticed (Figure $5 \mathrm{a}, \mathrm{b}$ ). These holes arise from the rapid depressurisation of the $\mathrm{CO}_{2}$ which forces its way back to the polymer-air interface during depressurisation. For cross-sectional TEM imaging, samples were partially treated with ethanol to etch and/or modify the PEO domains in order to increase the electron contrast and highlights the surface and internal morphology of the film (Figure 5c). At the surface of the film, undulating patterns of non-uniform PEO cylinders (dark contrast) was observed. Within and throughout the interior of the film, a well-resolved array of equally spaced ordered pores or lines was observed consistent with the expected etch/modification of the PEO domain by the ethanol treatment. The enhancement of the contrast can be associated with the partial crystallisation of the domains as crystalline PEO has much greater density $\left(1.24 \mathrm{~g} \mathrm{~cm}^{-3}\right)$ than amorphous PEO $\left(1.12 \mathrm{~g} \mathrm{~cm}^{-3}\right)$ [28]. The PEO cylinder diameter varied between 27-33 nm. Multiple layers of voids or spaces can be seen across the film thickness as the film thickness increases to $72 \mathrm{~nm}$. Continuous parallel layers of voids or elliptical ordered patterns is noticed depending on the orientation of the PEO cylinders. The void spaces formed during fast depressurisation through the rapid removal of $\mathrm{CO}_{2}$ from the swelled PEO sites providing additional thickness to the film. Another reason for the void generation could be due to a sudden increase in the viscosity of the polymers during fast depressurisation. The optimum depressurisation rate of $40 \mathrm{psi} / \mathrm{min}$ was found to produce uniform diameter PEO cylinders in hexagonal arrangements. By decreasing the depressurisation rate to $30 \mathrm{psi} / \mathrm{min}$, a narrow range of $\mathrm{PEO}$ cylinder diameter distribution observed but the film was distorted in several places (Figure $5 \mathrm{~d}$ ). Thus, discontinuous film with thickness around $50 \mathrm{~nm}$ were noted possibly due to high local concentration of $\mathrm{CO}_{2}$ during degassing resulted in the collapse of the ordered surface structure of the BCP films. Further decreasing the depressurisation rate to $20 \mathrm{psi} / \mathrm{min}$, thickness variations with mixed PEO cylinder orientation (both parallel and perpendicular) was observed throughout the film (Figure 5e). This observation is probably related to a large amount of trapped $\mathrm{CO}_{2}$ causing further film swelling. The flipping tendency is due to minimise the Gibbs energy of the system [5]. 

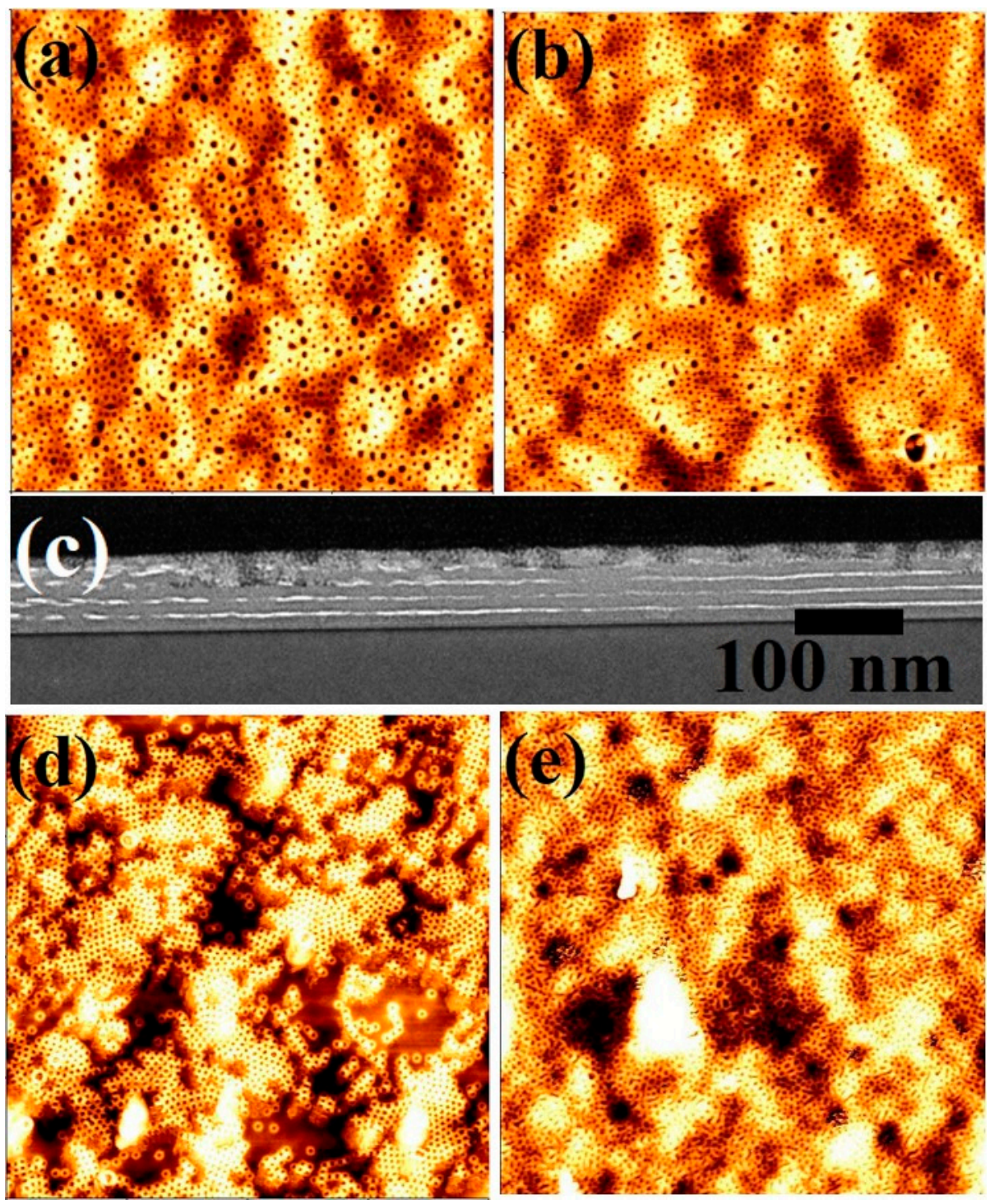

Figure 5. AFM topographic images of microphase separated 42,000-11,500 k PS- $b$-PEO thin films patterns under $\mathrm{SCF}$ annealing at $40^{\circ} \mathrm{C}$ for $30 \mathrm{~min}$ with different depressurization rate of (a) $120 \mathrm{psi} / \mathrm{min}$, (b) $60 \mathrm{psi} / \mathrm{min}$ (d) $30 \mathrm{psi} / \mathrm{min}$ and (e) $20 \mathrm{psi} / \mathrm{min}$. Scale bar: $4 \mu \mathrm{m}^{2}$. (c) FIB thinned cross-sectional TEM image of $\mathrm{S} 3$ after SCF annealing at $40{ }^{\circ} \mathrm{C}$ for $30 \mathrm{~min}$ with a depressurization rate of $120 \mathrm{psi} / \mathrm{min}$.

\subsection{Fabrication of BCP Nanopatterns on Graphoepitaxial Substrate}

In this study, we also examine whether the $\mathrm{scCO}_{2}$ annealing process could be used to achieve ordered BCP films on graphoepitaxial substrates, with different channels widths. A graphoepitaxial substrate was used to generate ordered microphase separated PS- $b$ PEO, S3 BCP nanopatterns. A $7 \mathrm{~nm}$ thick silica layer coated Si substrate with $50 \mathrm{~nm}$ deep topographically defined patterns of SiN sidewall was used as a substrate. The concentrations of the BCP-toluene solution for spin coating were calibrated to $0.5 \mathrm{wt} \%$ to avoid any overfilling within the channels. Figure 6a shows ordered arrays of dot patterns within channel widths of 120 and $240 \mathrm{~nm}$ after annealing in $\mathrm{scCO}_{2}$ at a temperature of $40^{\circ} \mathrm{C}$ and a pressure of $1200 \mathrm{psi}$ for $30 \mathrm{~min}$. Similarly ordered arrays were also realised for 160 and $320 \mathrm{~nm}$ channel widths as shown in Figure 6b,c, respectively. All the images reveal that the thickness variation increases and the ordered arrangement decreases with increasing channel widths. However, the BCP film all segregate into regular domain spacings of around $50 \mathrm{~nm}$ with mean PEO cylinder diameter of $27 \mathrm{~nm}$. This result indicates that the $\mathrm{scCO}_{2}$ annealing process is also applicable to use with graphoepitaxy-defined substrates. 


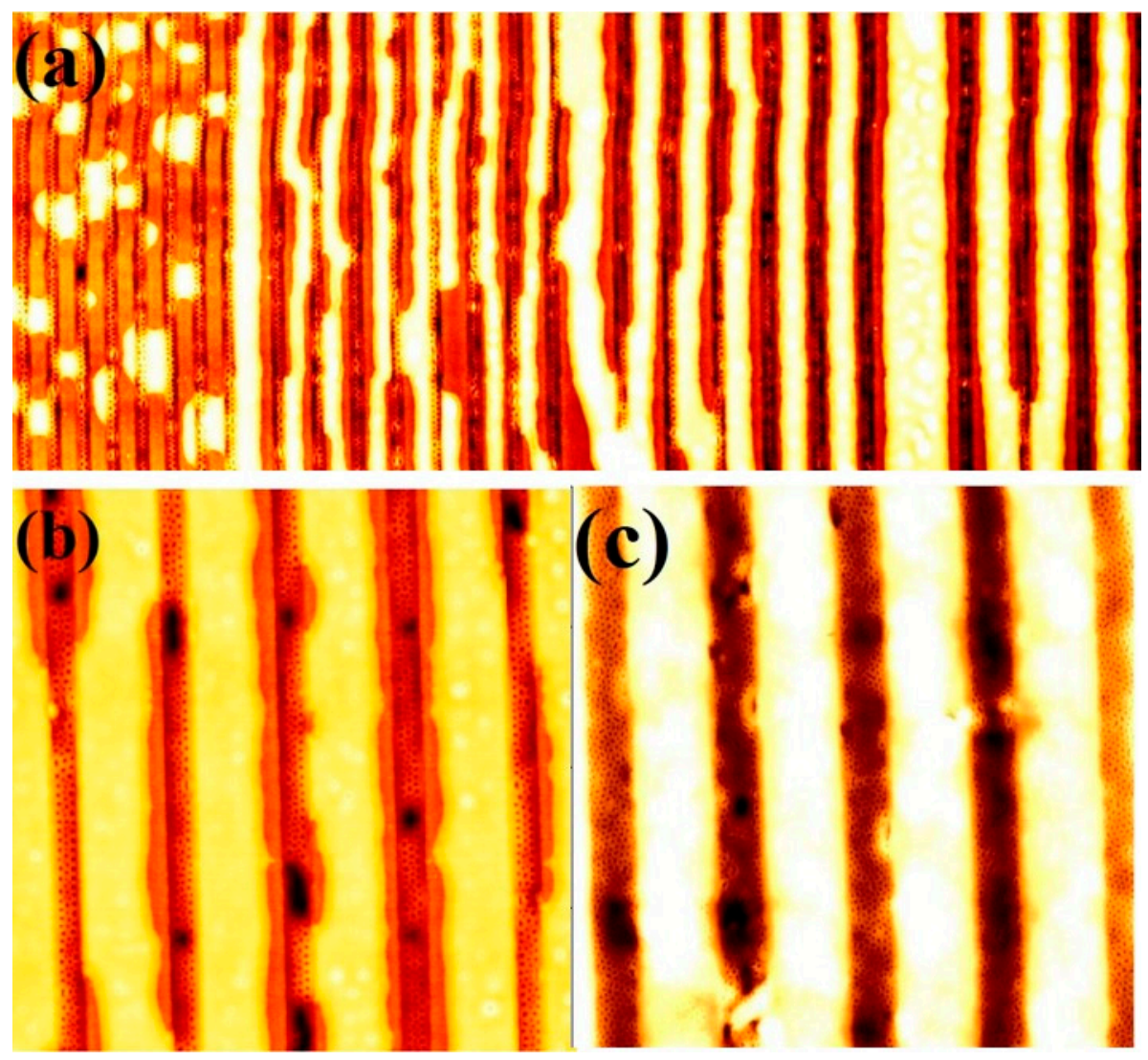

Figure 6. 42,000-11,500 PS- $b$-PEO thin film patterns on a graphoepitaxy substrate of different channel width under SCF annealing at $40{ }^{\circ} \mathrm{C}$ for $30 \mathrm{~min}$. Scale bar: (a) $5 \mu \mathrm{m} \times 12 \mu \mathrm{m},(\mathbf{b}, \mathbf{c}) 4 \mu \mathrm{m}^{2}$.

\subsection{Exploring SCF Annealing for Other BCP Composition}

The efficiency of the $\mathrm{scCO}_{2}$ annealing was also investigated for other $\mathrm{BCP}$ systems. In this context, an inverse PS- $b$-PEO $(16,000-39,500)$, Polystyrene- $b$-polymethylsiloxane (PS- $b$-PDMS) $(31,000-11,000)$ and Polystyrene- $b$-polylactic acid (PS- $b$-PLA) $(21,000-9000)$ BCPs were annealed in $\mathrm{scCO}_{2}$ for $30 \mathrm{~min}$ at a temperature of $40{ }^{\circ} \mathrm{C}$ with a pressure of 1200 psi. The AFM images shown in Figure 7 revealed the ordered arrangements for all of the BCPs. Figure 7a shows parallel orientation of PS cylinders inside PEO matrix with an average cylinder to cylinders spacing of $50 \mathrm{~nm}$ and cylinder diameter of $20 \mathrm{~nm}$. The self-assembly was realised at a lower temperature $\left(40^{\circ} \mathrm{C}\right)$ compared to those achieved by solvent annealing process $\left(60^{\circ} \mathrm{C}\right)$ [39]. A mixed orientation (parallel and perpendicular to the substrate surface) of PDMS cylinders inside the PS matrix is observed for $\mathrm{scCO}_{2}$ annealing with similar conditions (Figure $7 \mathrm{~b}$ ). The average cylinder to cylinders spacing is $44 \mathrm{~nm}$ and the cylinder diameter is $18 \mathrm{~nm}$. In comparison with the observation by Rasappa et al. [40] for the self-assembly achieved by solvent annealing, the average cylinder to cylinders spacing is slightly smaller compared to our study. Figure $7 \mathrm{a}, \mathrm{b}$ shows an enhanced surface roughness for PS- $b$-PDMS compared to the PS- $b$-PEO systems. In case of PS- $b$ PLA, similar $\mathrm{scCO}_{2}$ annealing parameters provides a hexagonal ordered perpendicularly oriented PLA cylinders inside PS matrix with a smooth surface (Figure 7c). The average cylinder to cylinders spacing is $34 \mathrm{~nm}$ whereas the cylinder diameter is $12 \mathrm{~nm}$. Generally, microphase separation for both of the cylinder forming and lamellar forming PS-PLA BCPs were realised by solvothermal annealing approach. For both of the systems, the periodicity between the blocks was observed smaller than $(\sim 5 \mathrm{~nm})$ that of observed in this study by SCF method [41,42]. This tendency might corresponds to more swelling tendency of PLA and PDMS by SCF compared to organic solvents. These results also indicate the efficiency of the $\mathrm{scCO}_{2}$ annealing to achieve ordered self-assembled patterns for a range of $\mathrm{BCP}$ systems. 

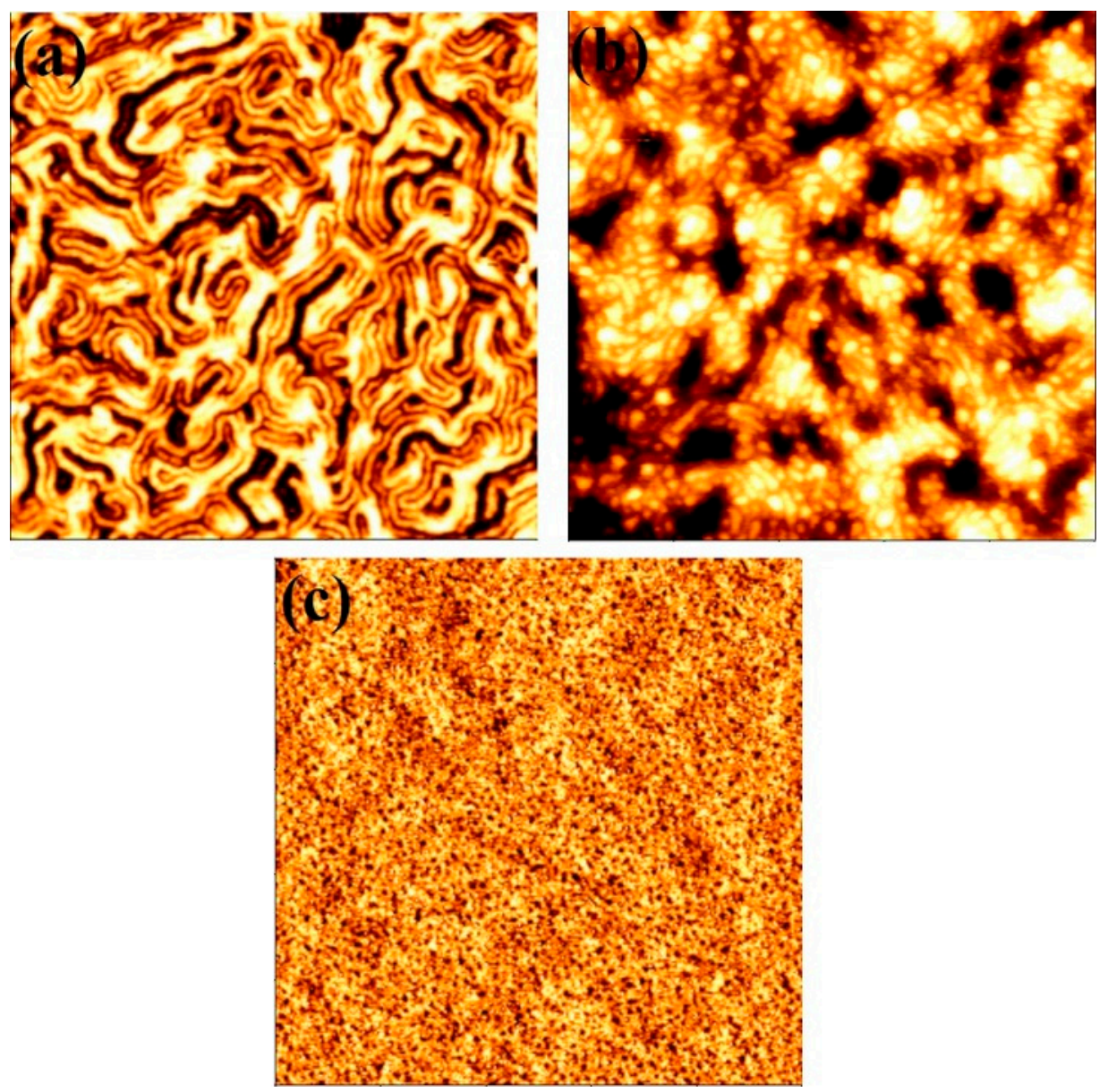

Figure 7. AFM topographic images of microphase separated thin films patterns under SCF annealing at $40{ }^{\circ} \mathrm{C}$ for $30 \mathrm{~min}$ at a pressure of 1200 psi for a range of BCP systems. (a) Inverse PS- $b$-PEO (16,00039,500), (b) Polystyrene-b-polymethylsiloxane (PS-b-PDMS) $(31,000-11,000)$ and (c) Polystyrene-bpolylactic acid (PS-b-PLA) (21,000-9000). Scale bar: $2 \mu \mathrm{m}^{2}$.

\section{Conclusions}

Self-assembled periodically ordered PS- $b$-PEO nanopatterns in thin films have been realised by annealing in $\mathrm{scCO}_{2}$ at low temperatures and pressure. A broad range of dimensional variation, i.e., mean centre-to-centre cylinder spacings (between 17-72 nm) and mean PEO cylinder diameters (7-38 nm) was achieved using different asymmetric molecular weight BCP systems. Significantly, a morphological evolution with parallel and/or perpendicular orientation of the PEO cylinders was also observed for different $\mathrm{BCP}$ molecular weight systems without disrupting the long-range order. High molecular weight systems required low $\mathrm{scCO}_{2}$ pressures to achieve microphase separated nanostructures compared to lower molecular weight $\mathrm{BCP}$ systems. Lower annealing temperature leads to discontinuous patterns including formation of holes in distinct places whereas higher temperature resulted in pattern degradation and surface roughening in the form of islands simultaneously varying PEO cylinder diameter. Similar structural variations were observed by varying film casting spin speeds. $\mathrm{CO}_{2}$ predominantly interacts with the PEO blocks compared to PS imparting higher mobility and surface energy, responsible for the microphase separation. The effective increase in the interaction parameter and decrease of the glass transition temperatures of the $\mathrm{BCP}$ films under $\mathrm{scCO}_{2}$, compared to vacuum, also leads to phase separation of the BCP thin films. Nanopores or nanocellular structures could be introduced into the films with a periodic surface arrangement by varying the $\mathrm{CO}_{2}$ depressurisation rate without the use of an additional solvent. The trapped residual solvent leads to morphological transition in the film structure. Complete elimination of 
$\mathrm{CO}_{2}$ at the end of the process makes the films useful for many technological and biological applications. This unique approach can also potentially be used to form highly ordered nanostructured surface arrangements on the graphoepitaxial substrate for nanolectronic devices. The efficiency of $\mathrm{scCO}_{2}$ annealing is established to generate ordered self-assembled patterns for a range of $\mathrm{BCP}$ systems.

Author Contributions: Contributed equally to conceptualisation, methodology, writing and analysis, T.W.C. and T.G.; contributed to conceptualisation, supervision S.B.; supervision, M.A.M. and J.D.H. All authors have read and agreed to the published version of the manuscript.

Funding: This research was funded by Science Foundation Ireland (Grants: 16/TIDA/4218 and 12/RC/2278).

Conflicts of Interest: The authors declare no conflict of interest.

\section{References}

1. Hamley, I.W. Introduction to Block Copolymers. Dev. Block Copolym. Sci. Technol. 2004, 1-29. [CrossRef]

2. Segalman, R.A. Patterning with Block Copolymer Thin Films Mater. Sci. Eng. R. Rep. 2005, 48, 191-226. [CrossRef]

3. Fasolka, M.J.; Mayes, A.M. Block Copolymer Thin Films: Physics and Applications. Annu. Rev. Mater. Sci. 2001, 31, 323-355. [CrossRef]

4. Hamley, I.W. Ordering in Thin Films of Block Copolymers: Fundamentals to Potential Applications. Prog. Polym. Sci. 2009, 34, 1161-1210. [CrossRef]

5. Mokarian-Tabari, P.; Collins, T.W.; Holmes, J.D.; Morris, M.A. Cyclical “Flipping” of Morphology in Block Copolymer Thin Films. ACS Nano 2011, 5, 4617-4623. [CrossRef]

6. Majewski, P.W.; Yager, K.G. Rapid Ordering of Block copolymer Thin Films. J. Phys. Condens. Matter. 2016, 28, 403002. [CrossRef] [PubMed]

7. Gotrik, K.W.; Ross, C.A. Solvothermal Annealing of Block Copolymer Thin Films. Nano Lett. 2013, 13, 5117-5122. [CrossRef]

8. Brassat, K.; Lindner, J.K.N. Nanoscale Block Copolymer Self-Assembly and Microscale Polymer Film Dewetting: Progress in Understanding the Role of Interfacial Energies in the Formation of Hierarchical Nanostructures. Adv. Mater. Interfaces 2020, 7, 1901565. [CrossRef]

9. Huang, W.H.; Chen, P.Y.; Tung, S.H. Effects of Annealing Solvents on the Morphology of Block Copolymer-Based Supramolecular Thin Films. Macromolecules 2012, 45, 1562-1569. [CrossRef]

10. Padinger, F.; Brabec, C.J.; Fromherz, T.; Hummelen, J.C.; Sariciftci, N.S. Fabrication of Large Area Photovoltaic Devices Containing Various Blends of Polymer and Fullerene Derivatives by using the Doctor Blade Technique. Opto-Electron. Rev. 2000, 8, $280-283$.

11. Koegler, W.S.; Patrick, C.; Cima, M.J.; Griffith, L.G. Carbon Dioxide Extraction of Residual Chloroform from Biodegradable Polymers. J. Biomed. Mater. Res. 2002, 63, 567-576. [CrossRef] [PubMed]

12. Ghoshal, T.; Senthamaraikannan, R.; Shaw, M.T.; Holmes, J.D.; Morris, M.A. 'Insitu' Hard Mask Materials: A New Methodology on Creation of Vertical Silicon Nanopillar and Nanowire Arrays. Nanoscale 2012, 4, 7743-7752. [CrossRef] [PubMed]

13. Ghoshal, T.; Fleming, P.G.; Holmes, J.D.; Morris, M.A. The Stability of “ $\mathrm{Ce}_{2} \mathrm{O}_{3}$ " Nanodots in Ambient Conditions: A Study using Block Copolymer Templated Structures. J. Mater. Chem. 2012, 22, 22949-22957. [CrossRef]

14. Kendall, J.L.; Canelas, D.A.; Young, J.L.; DeSimone, J.M. Polymerizations in Supercritical Carbon Dioxide. Chem. Rev. 1999, 99, 543-564. [CrossRef]

15. Li, Y.; Wang, X.; Sanchez, I.C.; Johnston, K.P.; Green, P.F. Ordering in Asymmetric Block Copolymer Films by a Compressible Fluid. J. Phys. Chem. B 2007, 111, 16-25. [CrossRef] [PubMed]

16. Tomasko, D.L.; Li, H.; Liu, D.; Han, X.; Wingert, M.J.; Lee, L.J.; Koelling, K.W. A Review of $\mathrm{CO}_{2}$ Applications in the Processing of Polymers. Ind. Eng. Chem. Res. 2003, 42, 6431-6456. [CrossRef]

17. Wissinger, R.G.; Paulaitis, M.E. Glass Transitions in Polymer $/ \mathrm{CO}_{2}$ Mixtures at Elevated Pressures. J. Polym. Sci. Part B Polym. Phys. 1991, 29, 631-633. [CrossRef]

18. Wissinger, R.G.; Paulaitis, M.E. Swelling and Sorption in Polymer-CO $\mathrm{CO}_{2}$ Mixtures at Elevated Pressures. J. Polym. Sci. Part B Polym. Phys. 1987, 25, 2497-2510. [CrossRef]

19. Koga, T.; Akashige, E.; Reinstein, A.; Brönner, M.; Seo, Y.-S.; Shin, K.; Rafailovich, M.; Sokolov, J.; Chu, B.; Satija, S. The effect of density fluctuations in supercritical fluids: New science and technology for polymer thin films. Phys. B: Condens. Matter 2005, 357, 73-79. [CrossRef]

20. Raudino, A.; Celso, L.F.; Triolo, A.; Triolo, R. Pressure-Induced Formation of Diblock Copolymer "Micelles" in Supercritical Fluids. A Combined Study by Small Angle Scattering Experiments and Mean-Field Theory. I. The Critical Micellization Density Concept. J. Chem. Phys. 2004, 120, 3489-3498. [CrossRef]

21. Kiran, E. Supercritical Fluids and Polymers-The Year in Review-2014. J. Supercrit. Fluids 2016, 110, 126-153. [CrossRef]

22. Farrell, R.A.; Fitzgerald, T.G.; Borah, D.; Holmes, J.D.; Morris, M.A. Chemical Interactions and their Role in the Microphase Separation of Block Copolymer Thin Films. Int. J. Mol. Sci. 2009, 10, 3671-3712. [CrossRef]

23. Arceo, A.; Green, P.F. Ordering Transition of Block Copolymer Films. J. Phys. Chem. B 2005, 109, 6958-6962. [CrossRef] 
24. Chen, Y.; Koberstein, J.T. Fabrication of Block Copolymer Monolayers by Adsorption from Supercritical Fluids: A Versatile Concept for Modification and Functionalization of Polymer Surfaces. Langmuir 2008, 24, 10488-10493. [CrossRef] [PubMed]

25. O'Driscoll, B.M.D.; Griffiths, G.H.; Matsen, M.W.; Hamley, I.W. Structure Variation and Evolution in Microphase-Separated Grafted Diblock Copolymer Films. Macromolecules 2011, 44, 8527-8536. [CrossRef]

26. Zhang, R.; Yokoyama, H. Fabrication of Nanoporous Structures in Block Copolymer using Selective Solvent Assisted with Compressed Carbon Dioxide. Macromolecules 2009, 42, 3559-3564. [CrossRef]

27. Ghoshal, T.; Biswas, S.; O’Regan, C.; Holmes, J.D.; Morris, M.A. Nanophase Separation and Structural evolution of Block Copolymer Films: A “Green” And “Clean” Supercritical Fluid Approach. Nano Res. 2015, 84, 1279-1292. [CrossRef]

28. Ghoshal, T.; Maity, T.; Godsell, J.F.; Roy, S.; Morris, M.A. Large Scale Monodisperse Hexagonal Arrays o Superparamagnetic Iron Oxides Nanodots: A Facile Block Copolymer Inclusion Method. Adv. Mater. 2012, 4, 7743. [CrossRef] [PubMed]

29. Ghoshal, T.; Shaw, M.T.; Bolger, C.T.; Holmes, J.D.; Morris, M.A. A General Method for Controlled Nanopatterning of Oxide Dots: A Microphase Separated Block Copolymer Platform. J. Mater. Chem. 2012, 22, 12083-12089. [CrossRef]

30. Wang, H.; Djurisic, A.B.; Chan, W.K.; Xie, M.H. Factors affecting phase and height contrastof diblock copolymer PS-b-PEO thin filmsin dynamic force modeatomic force microscopy. Appli. Surf. Sci. 2005, 252, 1092-1100. [CrossRef]

31. Zhang, Y.; Gangwani, K.K.; Lemert, R.M. Sorption and swelling of block copolymers in the presence of supercritical fluid carbon dioxide. J. Supercrit. Fluids 1997, 11, 115-134. [CrossRef]

32. Weidner, E.; Wiesmet, V.; Knez, Ž.; Škerget, M. Phase Equilibrium (Solid-Liquid-Gas) in Polyethyleneglycol-Carbon Dioxide Systems. J. Supercrit. Fluids 1997, 10, 139-147. [CrossRef]

33. Guadagno, T.; Kazarian, S.G. High-Pressure $\mathrm{CO}_{2}$-Expanded Solvents: Simultaneous Measurement of $\mathrm{CO}_{2}$ Sorption and Swelling of Liquid Polymers with In-Situ Near-IR Spectroscopy. J. Phys. Chem. B 2004, 108, 13995-13999. [CrossRef]

34. Gourgouillon, D.; Da Ponte, M.N. High Pressure Phase Equilibria for Poly(Ethylene Glycol)S $+\mathrm{CO}_{2}$ : Experimental Results and Modelling. Phys. Chem. Chem. Phys. 1999, 1, 5369-5375. [CrossRef]

35. Ghoshal, T.; Senthamaraikannan, R.; Shaw, M.T.; Holmes, J.D.; Morris, M.A. Fabrication of Ordered, Large Scale, HorizontallyAligned Si Nanowire Arrays based on an Insitu Hard Mask Block Copolymer Approach. Adv. Mater. 2014, 26, $1207-1216$. [CrossRef] [PubMed]

36. Ghoshal, T.; Maity, T.; Senthamaraikannan, R.; Shaw, M.T.; Carolan, P.; Holmes, J.D.; Roy, S.; Morris, M.A. Size and space controlled hexagonal arrays of superparamagnetic iron oxide nanodots: Magnetic studies and application. Sci. Rep. 2013, 3, srep02772. [CrossRef]

37. García-Turiel, J.; Jérôme, B. Solvent Retention in Thin Polymer Films Studied by Gas Chromatography. Colloid Polym. Sci. 2007, 285, 1617-1623. [CrossRef]

38. Wang, W.-C.V.; Kramer, E.J.; Sachse, W.H. Effects of high-pressure $\mathrm{CO}_{2}$ on the glass transition temperature and mechanical properties of polystyrene. J. Polym. Sci. Polym. Phys. Ed. 1982, 20, 1371-1384. [CrossRef]

39. Ghoshal, T.; Holmes, J.D.; Morris, M.A. Development of Ordered, Porous (Sub-25 nm Dimensions) Surface Membrane Structures Using a Block Copolymer Approach. Sci. Rep. 2018, 8, 7252. [CrossRef]

40. Rasappa, S.; Schulte, L.; Borah, D.; Hulkkonen, H.; Ndoni, S.; Salminen, T.; Senthamaraikanan, R.; Morris, M.A.; Niemi, T. Morphology evolution of PS-b-PDMS block copolymer and its hierarchical directed self-assembly on block copolymer templates. Microelectron. Eng. 2018, 192, 1-7. [CrossRef]

41. Cummins, C.; Tabari, P.M.; Andreazza, P.; Sinturel, C.; Morris, M.A. Solvothermal Vapor Annealing of Lamellar Poly(styrene)block-poly(d,l-lactide) Block Copolymer Thin Films for Directed Self-Assembly Application. ACS Appl. Mater. Interfaces 2016, 8 , 8295-8304. [CrossRef] [PubMed]

42. Cummins, C.; Mokarian-Tabari, P.; Holmes, J.D.; Morris, M. A Selective etching of polylactic acid in poly(styrene)-blockpoly(D,L)lactide diblock copolymer for nanoscale patterning. J. Appl. Polymer Sci. 2014, 131, 40795. [CrossRef] 